\title{
Mathematical modeling of Swine flu (H1N1) disease
}

\author{
${ }^{1}$ Ajay J. Patel, ${ }^{2}$ Dr.M.B.Prajapati, ${ }^{3}$ Dr.P.H.Bhathawala \\ ${ }^{1}$ Assistant Professor, Department of Mathematics, Government Science College, Idar, India \\ ${ }^{2}$ Professor,H.O.D. in Dept. of Mathematics, Hemchandracharya North Gujarat University, Patan, India \\ ${ }^{3}$ Professor, Dept. of Mathematics, Hemchandracharya North Gujarat University, Patan, India
}

\begin{abstract}
Swine flu (HINI) is prevalence due to increased infection rate around the world, as specially in India. A large number of humans die or have serious effects on the different states of India. In this paper we present an initial model with disease in different size population for the evolution of the infected people with Swine flu (H1Nl).We explore the dynamics of the Swine flu disease at the population level using an epidemiological model. Data of Statistic are used to estimate some of the parameters of the model and we will see spread of the disease in different scenarios.
\end{abstract}

Keywords: Swine flu Disease, Epidemiological model, HIN1, Pandemic, Mathematical model

\section{Introduction}

Swine flu influenza, also called pig influenza, Swine flu, hog flu and pig flu is an infection caused by any one of several types of Swine influenza viruses. Swine flu influenza (SIV) or Swine-origin influenza (SOIV) is any strain of the influenza family of viruses that is endemic in pigs. As of 2009 the well known SIV strains include influenza $C$ and the subtypes of influenza A known as H1N1, H1N2, H2N1, H3N1, H3N2 and H2N3.

Swine influenza virus is common throughout pig populations worldwide. Virus from pigs to human transmission is not common and does not definite lead to human flu, often resulting only in the blood. If transmission does cause human flu, it is called one type of Swine flu. People with regularly exposure to pigs are at increased risk of swine flu infection.

Flu is caused by influenza virus, and is spread mainly by sneezing, coughing, and close contact. Anyone can get flu, but the risk of getting flu is highest among children. Symptoms suddenly come on and may last several days. They can include: chills/fever, cough, fatigue, headache and runny or stuffy nose [1]. By flu some people much sicker than others. These people include people 65 older, young children and pregnant women and people with certain health conditions-such as lung, heart or kidney disease, nervous system disorders vaccination of flu is especially important for these people and any one in close contact with them. B flu lead to make existing medical conditions worse and Pneumonia. It can cause diarrhea and seizures in children [2].

India reported its first case on $13^{\text {th }}$ May, 2008. Most of cases reported subsequently were travel related cases among those traveling to India from affected countries. 12604 persons have been tested on $20^{\text {th }}$ and so far out of which 2401 are positive for Swine influenza A H1N1 [3].Meaning of Swine flu ( H1N1) is that Swine flu happen caused by H1N1

\section{Mathematical model}

We will now start Mathematical model for Swine flu (H1N1) for population. In epidemiology structure and ideas of mathematical modeling, we develop model for Swine flu (H1N1) disease after basic hypotheses. Total population $\mathrm{N}(\mathrm{t})$ is divided in following three subpopulations:

Susceptible $\mathrm{S}(\mathrm{t})$ : the persons in population who are not infected but may become infected

Infected $\mathrm{I}(\mathrm{t}):$ the persons in population infected by the Swine flu(H1N1)

Controlled $\mathrm{C}(\mathrm{t})$ : the persons in population who was infected but now they are free from Swine flu(H1N1).

Population of Susceptible $S(t)$ transits in infected population I $(t)$ with rate $\alpha$.Population of infected person I ( $t$ ) transits in controlled population $\mathrm{C}(\mathrm{t})$ with rate $\beta$.

First we assumed $Y$ is birth rate which is independent from time as well as natural death rate d. Transmission rate $\alpha$ is dependent on susceptible population $S(t)$ as well as infected population $I(t)$.Here we assume that newborn has probability to be healthy is 1 .

Death rate caused by Swine flu (H1N1) with rate $\delta$.

All persons in susceptible population $\mathrm{S}(\mathrm{t})$ have probability to be infected is equal.

A diagram of Swine flu (H1N1) disease on population is as follows. 


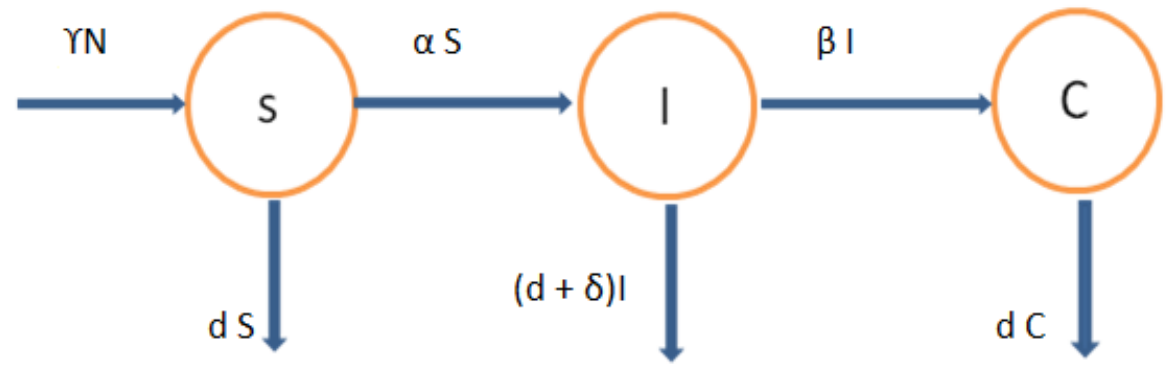

Fig.1. Diagram of the Swine flu (H1N1) disease on population

Table-1: Parameters of Mathematical model is as follows

\begin{tabular}{|l|l|}
\hline Parameter & \multicolumn{1}{c|}{ Description } \\
\hline$\delta$ & Death rate caused by Swine flu (H1N1) \\
\hline$\beta$ & Swine flu(H1N1) controlled rate \\
\hline$\alpha$ & Transmission rate \\
\hline $\mathrm{d}$ & Natural death rate \\
\hline$\Upsilon$ & Birth rate \\
\hline
\end{tabular}

With above assumptions, an epidemiological Mathematical model for Swine flu(H1N1) is following linear system of ordinary differential equations.

$S^{\prime}(\mathrm{t})=\Upsilon \mathrm{N}(\mathrm{t})-\mathrm{d} \mathrm{S}(\mathrm{t})-\alpha \mathrm{S}(\mathrm{t})$

$I^{\prime}(t)=\alpha S(t)-(d+\delta) I(t)-\beta I(t)$,

$\mathrm{C}^{\prime}(\mathrm{t})=\beta \mathrm{I}(\mathrm{t})-\mathrm{d} \mathrm{C}(\mathrm{t})$,

$\mathrm{N}(\mathrm{t})=\mathrm{S}(\mathrm{t})+\mathrm{I}(\mathrm{t})+\mathrm{C}(\mathrm{t})$

Where $\mathrm{I}(\mathrm{t}), \mathrm{S}(\mathrm{t})$ and $\mathrm{C}(\mathrm{t})$ denotes the three subpopulations at time $\mathrm{t}$. The representation of whole population in three different subpopulation in Fig. 1.

This mathematical model is used for estimate parameters related to Swine flu (H1N1).

\section{Scaling the model}

Now we scale the model .Idea develop in papers $[4,5]$ that how the scale the models with different populations size.

Now by using equations in (1) then we have,

$\mathrm{N}^{\prime}(\mathrm{t})=\Upsilon \mathrm{N}(\mathrm{t})-\mathrm{d} \mathrm{S}(\mathrm{t})-(\mathrm{d}+\delta) \mathrm{I}(\mathrm{t})-\mathrm{d} \mathrm{C}(\mathrm{t})$

Therefore

$\mathrm{N}^{\prime}(\mathrm{t})=(\Upsilon-\mathrm{d}) \mathrm{N}(\mathrm{t})-\delta \mathrm{I}(\mathrm{t})$

Dividing both member of (2) by $\mathrm{N}$, we have

$\mathrm{N}^{\prime} / \mathrm{N}=(\Upsilon-\mathrm{d})-\delta \mathrm{I}(\mathrm{t}) / \mathrm{N}(\mathrm{t})$

Now we define the following.

$$
\mathrm{s}=\mathrm{S} / \mathrm{N}, \mathrm{i}=\mathrm{I} / \mathrm{N}, \mathrm{c}=\mathrm{C} / \mathrm{N} \text {, }
$$

By equation (3) we get,

$\mathrm{N} / \mathrm{N}=\mathrm{Y}-\mathrm{d}-\delta \mathrm{i}$.

Now, we calculate the derivative of $\mathrm{s}$ by using (5)

$$
\mathrm{s}^{\prime}=\left(\mathrm{S}^{\prime} \mathrm{N}-\mathrm{SN}^{\prime}\right) / N^{2}=\mathrm{S}^{\prime} / \mathrm{N}-\mathrm{SN}^{\prime} / \mathrm{NN}=\mathrm{S}^{\prime} / \mathrm{N}-\mathrm{s}(\Upsilon-\mathrm{d}-\delta \mathrm{i}),
$$

And similarly,

$\mathrm{i}^{\prime}=\mathrm{I}^{\prime} / \mathrm{N}-\mathrm{i}(\Upsilon-\mathrm{d}-\delta \mathrm{i})$,

$\mathrm{c}^{\prime}=\mathrm{C}^{\prime} / \mathrm{N}-\mathrm{c}(\Upsilon-\mathrm{d}-\delta \mathrm{i})$

Now we use equation of system (1) and divide by $\mathrm{N}$, we get

$$
\mathrm{S}^{\prime} / \mathrm{N}=\Upsilon-\mathrm{d} \mathrm{S} / \mathrm{N}-\alpha \mathrm{S} / \mathrm{N}
$$

Substituting in equation (6) and using defined in (4) and using (8) we obtain following

$$
\mathrm{s}^{\prime}=\Upsilon-\mathrm{s}(\mathrm{t})(\Upsilon+\alpha-\delta \mathrm{i}(\mathrm{t})) \text {. }
$$

Similarly by using equation (1) scaled then we get

$\mathrm{i}^{\prime}(\mathrm{t})=\alpha \mathrm{s}(\mathrm{t})-\mathrm{i}(\mathrm{t})(\beta+\Upsilon+\delta-\delta \mathrm{i}(\mathrm{t}))$

$c^{\prime}(\mathrm{t})=\beta \mathrm{i}(\mathrm{t})-(\Upsilon-\delta \mathrm{i}(\mathrm{t})) \mathrm{c}(\mathrm{t})$,

$\mathrm{s}(\mathrm{t})+\mathrm{i}(\mathrm{t})+\mathrm{c}(\mathrm{t})=1$

This show that after scaling the model has been transformed

DOI: $10.9790 / 5728-1204051014 \quad$ www.iosrjournals.org 
Into a nonlinear we have

$\mathrm{s}(\mathrm{t})+\mathrm{i}(\mathrm{t})+\mathrm{c}(\mathrm{t})=1$, we can eliminate $\mathrm{c}(\mathrm{t})$ and consider the system.

$\mathrm{s}^{\prime}=\Upsilon-\mathrm{s}(\mathrm{t})(\Upsilon+\alpha-\delta \mathrm{i}(\mathrm{t}))$

$i^{\prime}(t)=\alpha s(t)-i(t)(\beta+\Upsilon+\delta-\delta i(t))$.

Some parameters of model can be estimated in following Table -2 .

Table - 2:

\begin{tabular}{|l|l|}
\hline Parameter & Values \\
\hline $\mathrm{r}$ & 0.02022 \\
\hline $\mathrm{d}$ & 0.0074 \\
\hline$\delta$ & 0.0005263 \\
\hline
\end{tabular}

The parameters of the model $\alpha$ and $\beta$ are unknown and we will find them in next discussion session.

\section{Discussion}

We are going to discuss in this session that Swine flu Cases report (2009-2015) of India [6] .In this report year wise number of reported case (positive case) and number of death caused by Swine flu (H1N1) given. By using this data controlled rate $(\beta)$ and Transmission rate $(\alpha)$ are calculated is as follows in Table -3

Table -3

\begin{tabular}{|l|l|l|l|l|}
\hline Year & Reported case & Death by Swine flu(H1N1) & $\begin{array}{l}\text { Controlled } \\
\text { Rate ( } \square \text { ) }\end{array}$ & $\begin{array}{l}\text { Transmission rate } \\
(\square)\end{array}$ \\
\hline 2009 & 27236 & 981 & 0.019740602 & 0.020478195 \\
\hline 2010 & 20604 & 1763 & 0.014166165 & 0.015491729 \\
\hline 2011 & 603 & 75 & 0.000396992 & 0.000453383 \\
\hline 2012 & 5044 & 405 & 0.00348797 & 0.003792481 \\
\hline 2013 & 5253 & 699 & 0.00342406 & 0.003949624 \\
\hline 2014 & 937 & 218 & 0.000540602 & 0.000704511 \\
\hline 2015 & 12963 & 774 & 0.009164662 & 0.009746617 \\
\hline
\end{tabular}

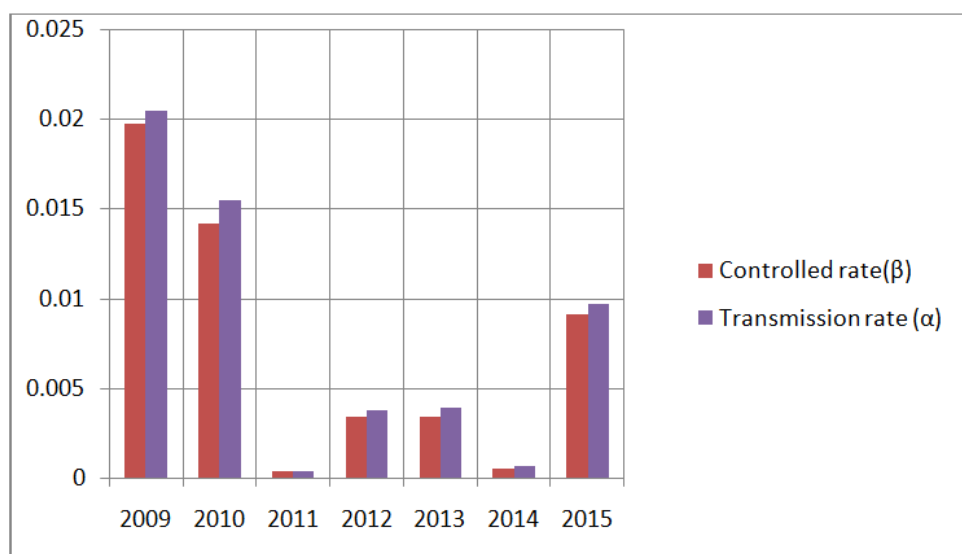

Fig. 2 Comparison of controlled rate and transmission rate

By above Fig. 2 that can be shown that in year 2009 and 2010 Transmission rate $(\alpha)$ was very high ,but by taken sudden action therefore controlled rate $(\beta)$ was also high. We can observe that year wise value of $\alpha$ and $\beta$ are varying with respect to time. Now we discuss about states in which number of reported case are high of Swine flu (H1N1). According to the released data by the Health Ministry [7,8], if we calculate percentage of controlled rate out of reported case. Table -4 is as follows.

Table - 4

\begin{tabular}{|l|l|l|l|}
\hline State & Percentage & Reported cases & Number of deaths \\
\hline Rajasthan & 93.67281598 & 6559 & 415 \\
\hline Gujarat & 93.41031563 & 6495 & 428 \\
\hline Delhi & 99.70993474 & 4137 & 12 \\
\hline Maharashtra & 90.15 & 4000 & 394 \\
\hline Madhya Pradesh & 86.31578947 & 2185 & 299 \\
\hline Telangana & 96.4953271 & 2140 & 75 \\
\hline Karnataka & 96.9996341 & 2733 & 82 \\
\hline
\end{tabular}


Fig. 3

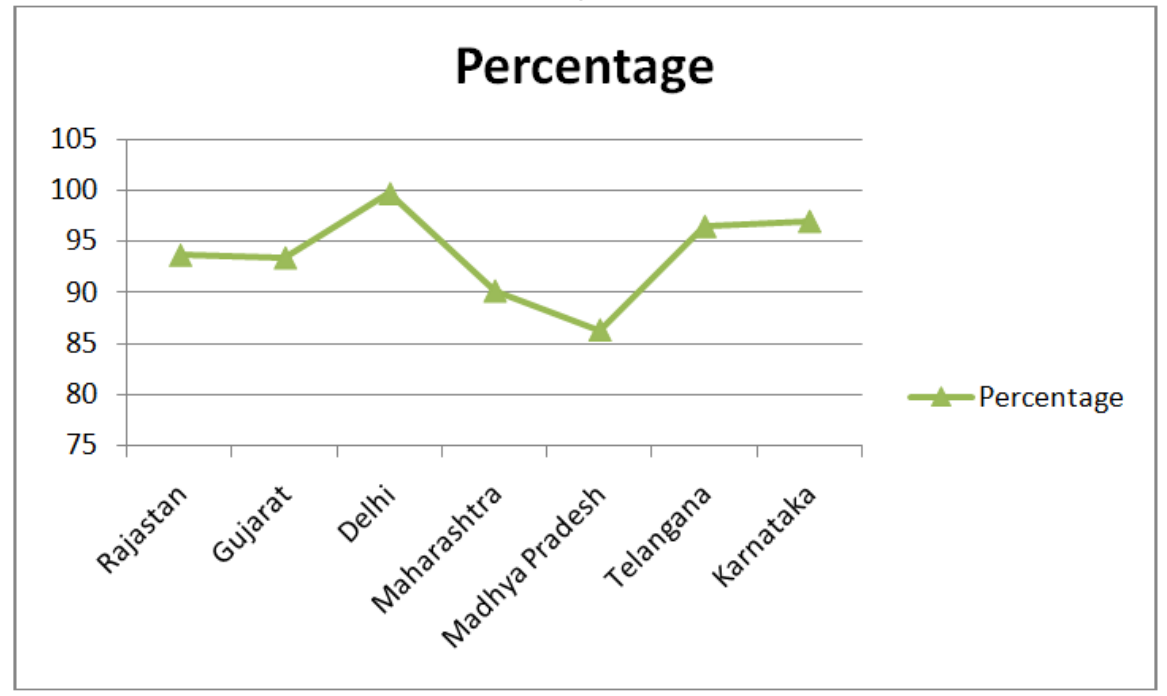

Above Fig. 3 is a show that percentage of controlled rate from reported case is more than 85 .

Now we discuss about states in which number of reported case are low of Swine flu (H1N1). According to the released data by the Health Ministry if we calculate percentage of controlled rate out of reported case. Table -5 is as follows.

Table - 5

\begin{tabular}{|l|l|l|l|}
\hline State & Percentage of Controlled Rate & Reported case & Death By Swine Flu(H1N1) \\
\hline Punjab & 76.65198238 & 227 & 53 \\
\hline Andhra Pradesh & 69.44444444 & 72 & 22 \\
\hline Uttar Pradesh & 78.18181818 & 165 & 36 \\
\hline Kerala & 52 & 25 & 12 \\
\hline West Bengal & 58.62068966 & 58 & 24 \\
\hline Manipur & 60 & 5 & 2 \\
\hline
\end{tabular}

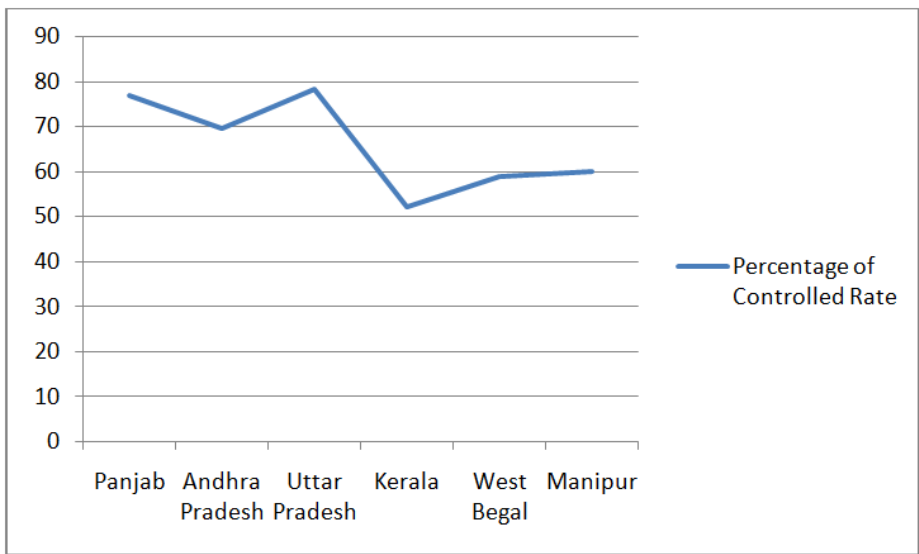

Fig. 4

Above Fig. 4 is shows that percentage of controlled rate from reported case is approximately 60 .

\section{Conclusion}

Mathematical modeling is important tool for understanding the dynamics of epidemic disease. According to the released data by the Health Ministry calculated controlled rate and transmission rate very much differ by time .by Fig. 2 we can observe that there is no long difference between controlled rate and transmission rate.States in which number of reported case are high of Swine flu (H1N1), if we calculate percentage of controlled rate out of reported case then that is more than 85. States in which number of reported case are low of Swine flu (H1N1), if we calculate percentage of controlled rate out of reported case that is near to 60. 


\section{References}

[1]. Safety Precautions to Deal with H1N1 Swine Flu: Symptoms of Swine Flu (http://www.thefitindian.com/h1n1-virus-swine-flu/) [Accessed: Feb.27, 2015].

[2]. Swine Flu and You" (http://www.cdc.gov/swineflu/swineflu_you.htm) CDC. 2009-04- 26. [Accessed: Feb. 27, 2015].

[3]. Pandemic Influenza A H1N1: Directorate General of Health Services Ministry of Health and Family Welfare Government of India, (http://karhfw.gov.in/H1N1/5.\%20Clinical\%20Management\%20Protocol Pandemic\%20influenza\%20A\%20H1N1.pdf) [Accessed Feb. 26, 2015].

[4]. M. Martcheva, C. Castillo Chavez, Diseases with chronic stage in population with varying size, Math. Biosci. 182 (2003) 1-25.

[5]. J. Mena-Lorca, H.W. Hethcote, Dynamic model of infectious diseases as regulators of population size, J. Math Biol. 30 (1992) 693716.

[6]. Swine flu outbreak: 774 deaths, 13,000 cases set alarm bells ringing (Source: Union Ministry of health \& Family Welfare) (http://www.hindustantimes.com/india-news/swine-flu-outbreak-743-deaths-12000 positive-cases- setalarm-bells-ringingacross-india/article1-1319158.aspx) (Updated: Feb 22, 2015).

[7]. PTI(March 19,2015).”Swine flu toll inches towards 1900. The Hindu. Retrieved March 20,2015.

[8]. "Swine flu death toll nears 600 in India. The times of India.17 February 2015.Retrieved 21 February 2015 